OPEN ACCESS

Edited by:

Amy Marks,

Suffolk University, United States

Reviewed by:

Kida Ejesi,

Boston Children's Hospital and

Harvard Medical School,

United States

Lacey Hilliard,

Suffolk University, United States

*Correspondence:

Sandy Chwastek

Sandy.Chwastek@ruhr-uni-bochum.de

Specialty section:

This article was submitted to

Public Mental Health,

a section of the journal

Frontiers in Psychiatry

Received: 19 June 2020 Accepted: 21 December 2020

Published: 27 January 2021

Citation:

Chwastek S, Leyendecker B, Heithausen A, Ballero Reque $C$ and Busch J (2021) Pre-school Teachers'

Stereotypes and Self-Efficacy are

Linked to Perceptions of Behavio Problems in Newly Arrived Refugee

Children.

Front. Psychiatry 11:574412. doi: 10.3389/fpsyt.2020.574412

\section{Pre-school Teachers' Stereotypes and Self-Efficacy are Linked to Perceptions of Behavior Problems in Newly Arrived Refugee Children}

\author{
Sandy Chwastek*, Birgit Leyendecker, Anna Heithausen, Cristina Ballero Reque and \\ Julian Busch
}

Faculty of Psychology, Child and Family Research, Ruhr-University Bochum, Bochum, Germany

Introduction: Since 2015, increased numbers of refugee families with pre-school-aged children have arrived in Germany. In pre-schools, teachers' professional competence for teaching those children and adapting to their socio-emotional needs has become increasingly important. Previous research linked teachers' stereotypes and cultural beliefs to their self-efficacy and enthusiasm when teaching immigrant children. This study investigated the links between domains of pre-school teachers' professional competence (i.e., negative stereotypes, multicultural beliefs, self-efficacy, and enthusiasm when teaching newly arrived refugee children), and examined whether teachers' professional competence was linked to their perceptions of newly arrived refugee children's behavior problems.

Method: In a cross-sectional self-report survey, $N=147$ German pre-school teachers reported on their professional competence and completed the Strengths and Difficulties Questionnaire (SDQ) for a selected refugee child from their pre-school group. We used regression modeling to link teachers' negative stereotypes and multicultural beliefs to their self-efficacy and enthusiasm for teaching refugee children. Next, we examined the links between teachers' beliefs, values, and motivational orientations to their ratings on the SDQ subscales. Last, we linked demographic data on teachers and children to teachers' professional competence and SDQ ratings.

Results: Teachers with more negative stereotypes toward newly arrived refugee children and less agreement with multicultural beliefs reported lower self-efficacy and enthusiasm for teaching newly arrived refugee children. Teachers with more negative stereotypes perceived more hyperactivity/inattention and total difficulties. Teachers with higher self-efficacy perceived less hyperactivity/inattention, less total difficulties, and more prosocial behavior. Additionally, teachers who had more experience with refugee children reported more negative stereotypes and higher agreement with multicultural beliefs. Teachers having more overall work experience perceived more total difficulties. Boys were perceived to display more externalizing behavior problems, less prosocial behavior, and more total difficulties. Older children were perceived as displaying more prosocial behavior and children from African countries were perceived as displaying more conduct problems. 


\begin{abstract}
Discussion: Our findings suggest that pre-school teachers' stereotypes and self-efficacy might be related to perception biases concerning newly arrived refugee children's externalizing behavior problems. Implications for the professional development of pre-school teachers and teacher-informant diagnostics of refugee children's socio-emotional needs are discussed.
\end{abstract}

Keywords: mental health, refugee, pre-school, teacher, perception, SDQ, early education, childcare

\section{INTRODUCTION}

Since 2015, large numbers of forcibly displaced children under the age of six have been arriving in Germany from conflicted and deprived regions [46.316 in 2019; (1)]. Increased levels of behavior problems of refugee children have been found in several countries, including evidence on the early childhood period (2-5). For example, elevated levels of aggressive behaviors, inattention, and peer problems were also found in refugee children attending early education programs in Germany when compared to norm data (6). Refugee children are exposed to large numbers of risk factors throughout migration periods. Many of those risk factors render the children extremely sensitive to the quality of child care services (7-9). Early childhood teachers' accurate perceptions and handling of refugee children's socioemotional needs can promote adjustment processes and positive development during resettlement periods.

\section{Early Education and Challenges for Teachers}

In Germany, the great majority of all children aged three to six attend pre-schools, which are required to provide the learning basis for transitioning into primary school at around age 6 (10). They are in a unique position to support children at risk, as they can consider their specific needs without having to focus on strict academic content. Prior, early education was found to reduce the impact of risk factors on child development and school performance in low-income children $(11,12)$. Due to their backgrounds and experiences, such as interruption of formal education, young refugee children require teachers to be more flexible and to consider their specific needs (13). However, teachers often lack experience or training for working with refugee children. Teachers reported feeling insecure in effectively detecting and serving refugee children's specific needs (14-16) and to find overcoming language barriers as well as communication with the parents difficult (17). Enhancing teachers' abilities to detect specific needs and behavior problems can improve the positive impact of early education on refugee children. Especially when identifying socio-emotional needs in refugee children, understanding behaviors, overcoming stigma, cultural and linguistic barriers, engaging with parents, and having a Western understanding of mental health were identified as challenging for teachers (18). Here, teachers' professional competence seems to play an important role. To the best of our knowledge, no study has yet addressed the relationship between pre-school teachers' professional competence and their perceptions of behavior problems in refugee children.

\section{Definition of Constructs}

In their model of professional competence, Hachfeld et al. (19) define teachers' professional competence as an important component of effective teaching processes in multicultural settings. Teachers' beliefs and values (comprising stereotypes and cultural beliefs) and teachers' motivational orientations (comprising self-efficacy and enthusiasm for teaching immigrant students), amongst others, were identified as central domains influencing the teaching of culturally diverse children. In this study, we selected our constructs based on this model. We focus on multicultural beliefs, which are, besides colorblind beliefs, an aspect of cultural beliefs. Teachers with a higher agreement with multicultural beliefs recognize that students from different sociocultural backgrounds have different perspectives and beliefs, value their students' different backgrounds as enriching and are open to embracing them in their teaching (20). This is opposed to colorblind beliefs. Teachers with colorblind beliefs believe that students' different cultural backgrounds should not be taken into account while teaching and teachers should focus on students' similarities (20). Multicultural beliefs were linked to more reported willingness to adapt one's teaching to immigrant students (19) such as ensuring that all students, despite their different cultural or linguistic backgrounds, are able to follow the lessons.

Hachfeld et al. (19) define stereotypes as negative expectancies toward immigrant students' educational engagement and motivations. We narrow down the definition to the extent to which the teachers perceive newly arrived students' refugee backgrounds as a burden for teaching. Self-efficacy and enthusiasm are looked at specifically in the context of teaching immigrant students (19). Following the model, self-efficacy is defined as the teachers' beliefs in their capabilities to successfully organize and execute specific teaching tasks in a particular context (21). We define teachers' enthusiasm as the degree of positive experiences during teaching (22) and their positive attitude to work with culturally diverse children. Differently to Hachfeld et al. (19), we relate teachers' professional competence explicitly to newly arrived refugee children in pre-school context instead of immigrant students in general.

\section{Prior Research on the Relations of Teacher's Professional Competence}

Multicultural beliefs were related to higher levels of self-efficacy and enthusiasm for teaching immigrant students as well as less negative stereotypes when teaching them $(19,23)$, and were negatively related to prejudicial thoughts (20). Expanding those findings, Bangura (24) found cultural awareness to positively 
predict multicultural self-efficacy of teachers in training. Similar to multicultural beliefs, perceiving immigrant students as an asset instead of viewing them negatively was related to higher immigration-related self-efficacy in primary and secondary school teachers (25). Although large numbers of pre-school-aged refugee children have arrived in Germany, Hachfeld's et al. (19) model has not yet been applied to investigate adaptations of early education to refugee children's specific needs.

\section{Prior Research on Professional Competence and the Perception of Students}

Evidence suggests that teachers' professional competence influences their perceptions of children's behavior problems in educational settings. Different kinds of teachers' beliefs such as those concerning student skills and performances were linked to teachers' perceptions, judgments, and behaviors in the classroom (26). We assume that especially stereotypes and multicultural beliefs are linked to teachers' perceptions of behavior problems in refugee children. The term refugee has the potential to trigger bias in teachers, depending on their stereotypes toward traits associated with this term and their multicultural beliefs. Supporting this notion, students' ethnicity and skin color were linked to teacher ratings and expectations toward students' behavior as well as the feedback teachers provided during instructions (27). Teachers also attributed lower achievement scores to children who had ethnic first names (28). While distinct evidence for pre-school-aged children is limited, similar results were found for assessments of students' performance in primary schools (29). Evidence suggests that teachers report more behavior problems for certain subgroups of immigrant or minority children $(30,31)$. According to these findings, more stereotypes and less agreement with multicultural beliefs should lead to focusing on children's difficulties instead of their strengths and in consequence to increased perceptions of behavior problems. In contrast, high self-efficacy and enthusiasm could have opposite effects. Along these lines, studies found teachers' self-efficacy beliefs to be associated with their sense of efficacy in resolving cultural conflicts (32). Additionally, Gibbs (33) discussed that teachers' sense of control influences how they think, feel, and teach. Thus, higher self-efficacy could be related to lower teacher's perceptions of behavior problems in refugee children.

\section{The Association of Teachers' Perceptions and Student Outcomes}

Assessing teachers' perspectives on students in early education is crucial, as teachers' expectation biases were found to have effects on long-term student performance and also to partly mediate the effects of student characteristics on students' performance (34). Understanding the behavior problems of students increases the odds of teachers' readiness to help them (35). Furthermore, perception biases can put culturally and linguistically diverse children at a disadvantage due to misperceptions of their true learning needs. Brown (36) found teachers to misperceive foreign child behaviors as disabilities, leading to erroneous placements in language disability interventions.

Teachers' professional competence was also directly linked to motivation and achievements in students. In a systematic review of 34 articles on learning problems in refugee children, Graham et al. (37) found teacher stereotyping and low expectations to be two of the major risk factors for their students' learning problems. Similarly, teachers' self-efficacy was linked to teachers' behavior, such as trying out new techniques and being more persistent while helping, to students' academic outcomes (38), and it positively influences students' motivation and academic achievements (39). Teachers' enthusiasm was found to predict students' interests (40) and, through instructional quality, students' outcomes (41). According to these findings, accurate pre-school teachers' perceptions, along with their appropriate behavior and guidance, could help refugee children to build strong learning foundations for the transition into primary school.

\section{This Study}

To date, the links between teachers' attitudes and views on the behavior of newly arrived refugee children within early education settings are understudied. However, teachers are regular informants on children's behavior problems and thus important to understand newly arrived refugee children's socioemotional needs. Therefore, we need to better understand (A) pre-school teachers' professional competence when teaching refugee children and (B) how teachers' professional competence facilitates serving the specific socio-emotional needs of those children. For this purpose, the present study investigates links between teachers' stereotypes, multicultural beliefs, self-efficacy, enthusiasm, and their perceptions of behavior problems in young refugee children. We hypothesize that $(\mathrm{H} 1)$ teachers with less negative stereotypes and higher agreement with multicultural beliefs toward refugee children are likely to display increased levels of self-efficacy and enthusiasm when teaching newly arrived refugee children; (H2) teachers with more negative stereotypes and less agreement with multicultural beliefs are likely to perceive more behavior problems in newly arrived refugee children; (H3) teachers with higher self-efficacy and enthusiasm are likely to perceive fewer behavior problems in newly arrived refugee children. Additionally, we link the most important demographic child and teacher data to teachers' competence and ratings on behavior problems. This study provides important evidence on the teacher-related determinants of responding to the mental health needs of newly arrived refugee children in early education services. Implications for the professional development of pre-school teachers and their work with refugee children are discussed.

\section{MATERIALS AND METHODS}

\section{Procedure}

We surveyed teachers who worked in pre-school facilities in the German federal state of North Rhine-Westphalia (NRW) online between May and July 2018. NRW received more than one quarter of all refugees in Germany. The survey period 
corresponds with the last quarter of the German academic year in pre-schools. First, we advertised our online survey to teachers in pre-schools via telephone, and later additionally via e-mail to increase the number of participants. When contacting pre-schools, we made sure to include both rural and urban areas. This sampling strategy intended to diversify our study sample increasing the generalizability of our results. Later, we additionally contacted pre-school teachers via a few selected social media channels, while clearly stating our inclusion criteria. Preschool teachers were included if they worked in pre-schools within NRW with at least one refugee child in their group who arrived after the year 2014. In each pre-school group, only one teacher was asked to participate. This ensured that children were not rated twice and children and groups were independent within our sample. Teachers filled in an online survey using the platform "Qualtrics" (SAP). They were asked to report on their professional competence and on the behavior problems of one selected refugee child of their group. Teachers were asked to select the child that had been attending their pre-school group for the longest period. As an incentive for participation, two tablets were raffled among the participants. The study protocol was approved by the Ethics Committee of the Faculty of Psychology of the Ruhr-University Bochum.

\section{Participants}

Overall, $N_{\text {total }}=240$ teachers accessed the survey. We filtered out flawed datasets based on missing data analysis and, in preparation for statistical modeling, visual inspection of residual plots. We only considered fully completed questionnaires for further analysis. $N=11$ teachers left the survey after filling in their demographic data and $n=82$ teachers after filling in the scales of teachers' competence. We assume that those participants were not interested to fully complete the survey for unknown and random reasons. The effective sample consisted of $N=147$ early childhood teachers. Table 1 shows descriptive information on the participating teachers and the pre-schools they work in. Notably, more than two-thirds of teachers reported having "rather a lot" or "a lot" of experience working with refugee children. The most common languages spoken by newly arrived children in the pre-school facilities were Arabic (in 82.19\% of all participating pre-schools), Kurdish (44.52\%), Albanian (39.73\%), Farsi (29.45\%), and Serbian (21.23\%). All children in this study learned German as their second language. The regional distribution of the facilities was nearly equally spread, with $46.94 \%$ being in rural or rather rural and $53.06 \%$ being in urban or rather urban areas. Table 2 provides demographic information on the assessed refugee children. The most common countries of origin were Syria (28.35\%), Iraq (10.24\%), and Afghanistan (7.09\%).

\section{Measurement}

Teachers completed a set of standardized self-report questionnaires. First, teachers reported on their personal backgrounds and the pre-school facilities. Second, following the conceptual propositions by Hachfeld et al. (23) and Hachfeld et al. (19), teachers reported on their stereotypes and multicultural beliefs as central domains of their beliefs and values, and on
TABLE 1 | Descriptives on pre-school teachers and facilities.

\begin{tabular}{|c|c|c|c|c|c|c|}
\hline & $\mathbf{M}$ & SD & Mdn & Min & Max & \\
\hline Age $(n=142)$ & 41.12 & 11.88 & 42.5 & 19 & 63 & \\
\hline $\begin{array}{l}\text { Work experience in } \\
\text { months }(n=145)\end{array}$ & 229.22 & 142.75 & 240 & 9 & 528 & \\
\hline \multirow[t]{2}{*}{ Gender $(n=147)$} & \multicolumn{5}{|l|}{ Male } & $4.76 \%$ \\
\hline & \multicolumn{5}{|l|}{ Female } & $95.24 \%$ \\
\hline \multirow{3}{*}{$\begin{array}{l}\text { School-leaving } \\
\text { qualification }(n=147)\end{array}$} & \multicolumn{5}{|c|}{ Secondary school certificate } & $36.73 \%$ \\
\hline & \multicolumn{5}{|c|}{ Vocational diploma } & $43.54 \%$ \\
\hline & \multicolumn{5}{|l|}{ A-Levels } & $19.73 \%$ \\
\hline \multirow[t]{3}{*}{ Qualification $(n=146)$} & \multicolumn{5}{|c|}{ Educator } & $78.08 \%$ \\
\hline & \multicolumn{5}{|c|}{$\begin{array}{l}\text { Employee with social and curative } \\
\text { school qualification }\end{array}$} & $8.22 \%$ \\
\hline & \multicolumn{5}{|l|}{ Other } & $13.69 \%$ \\
\hline \multirow{3}{*}{$\begin{array}{l}\text { Role at the facility } \\
(n=147)\end{array}$} & \multicolumn{5}{|c|}{ Pre-school educator } & $37.41 \%$ \\
\hline & \multicolumn{5}{|c|}{ Pre-school manager } & $53.74 \%$ \\
\hline & \multicolumn{5}{|l|}{ Other } & $8.84 \%$ \\
\hline \multirow{4}{*}{$\begin{array}{l}\text { Work experience with } \\
\text { refugee children } \\
(n=144)\end{array}$} & \multicolumn{5}{|c|}{ No experience } & $0.69 \%$ \\
\hline & \multicolumn{5}{|c|}{ Rather no experience } & $29.17 \%$ \\
\hline & \multicolumn{5}{|c|}{ Rather a lot of experience } & $52.78 \%$ \\
\hline & \multicolumn{5}{|c|}{ A lot of experience } & $17.36 \%$ \\
\hline \multirow{3}{*}{$\begin{array}{l}\text { Own migrant } \\
\text { background }^{\mathrm{a}}(n=147)\end{array}$} & \multicolumn{5}{|l|}{ Yes } & $10.88 \%$ \\
\hline & \multicolumn{5}{|l|}{ No } & $89.12 \%$ \\
\hline & M & SD & Mdn & Min & Max & \\
\hline $\begin{array}{l}\text { Total number of children in } \\
\text { facility }(n=146)\end{array}$ & 74.36 & 39.03 & 67 & 10 & 369 & \\
\hline $\begin{array}{l}\text { Newly arrived refugee } \\
\text { children }^{\mathrm{b}}(n=137)\end{array}$ & 18.09 & 10.18 & 19 & 1 & 36 & \\
\hline $\begin{array}{l}\text { Current number of refugee } \\
\text { children }(n=142)\end{array}$ & 14.16 & 9.54 & 13.5 & 1 & 31 & \\
\hline
\end{tabular}

n, number of cases; $M$, mean; SD, standard deviation; Mdn, median; Min, minimum stated by participants; Max, maximum stated by participants. ${ }^{a}$ Either one parent or the teachers themselves migrated to Germany. ${ }^{b}$ Newly arrived refugee children within the last 4 years.

their self-efficacy and enthusiasm for teaching refugee children as central indicators for their motivational orientations. Third, teachers reported on behavior problems of a systematically selected child using a standardized scale. For controlling order effects, scale items were presented randomly per construct. Mean values were computed for each scale of professional competence.

\section{Demographic Information on the Teachers and Pre-school Facilities}

We obtained socio-demographic information on the teachers (gender, age, professional qualification, position within the facility, experiences in educational work in general and with refugee children, migration background) and information on newly arrived children in the pre-school facilities (number of children within the facility, number of refugee children within the facility within the last four years, current number of refugee children within the facility, languages spoken by the refugee children, location of the facility). In addition, teachers provided information on the socio-demographic backgrounds of the 
TABLE 2 | Descriptives on refugee children.

\begin{tabular}{lcccccc}
\hline & M & SD & Mdn Min Max \\
\hline Age in months $(n=145)$ & 60 & 14.47 & 60 & 15 & 83 \\
Time in pre-school in months $(n=145)$ & 20.75 & 11.3 & 20 & 2 & 66 \\
Time in Germany in months $(n=104)$ & 32.8 & 14.69 & 36 & 2 & 65 \\
\hline
\end{tabular}

\begin{tabular}{llr}
\hline & & Rel number \\
\hline Gender $(n=146)$ & Female & $50.68 \%$ \\
& Male & $49.32 \%$ \\
Region of origin $(n=127)$ & Southeastern Europe & $12.59 \%$ \\
& Africa & $10.23 \%$ \\
& Western Asia & $47.25 \%$ \\
& South and Eastern Asia & $11.02 \%$ \\
& Other & $18.90 \%$ \\
\hline
\end{tabular}

n, number of cases; M, mean; SD, standard deviation; Mdn, median; Min, minimum stated by participants; Max, maximum stated by participants. Southeastern Europe = Albania, Greece, Montenegro, Romania, Serbia. Africa = Egypt, Eritrea, Morocco, Nigeria. Western Asia = Iran, Iraq, Syria, Turkey. South and Eastern Asia = China, Pakistan, Afghanistan.

selected children (gender, age, time spent within the facility, time spent in Germany, country of origin).

\section{Teachers' Stereotypes and Multicultural Beliefs}

In our study, stereotypes toward refugee children reflect the extent to which the teachers perceived newly arrived children's refugee backgrounds as a burden for teaching. We selected items following the SIMCUR survey (unpublished) that measured teachers' stereotypes toward immigrant children in primary schools and adapted wording to early education contexts (i.e., exchanging words such as school and pre-school). Items for the SIMCUR survey were constructed following the multicultural beliefs and stereotype scales from Hachfeld et al. (23). Whereas, the latter focused on students' school-related motivation and effort, items in the SIMCUR survey were framed to address newly arrived children's challenges in pre-school such as coping with the new surroundings and needing additional support. We assessed stereotypes using a 4-point Likert scale ( $1=$ not accurate, 4 = very accurate).

According to Hachfeld et al. (20), multicultural beliefs measure how strongly teachers endorse that cultural backgrounds of refugee children should be considered in teaching. We selected four items of the Teacher's Cultural Beliefs Scale [TCBS; (20)] and adapted wording to early education contexts. In line with the TCBS, we used a 6-point Likert scale (1 $=$ not accurate, $6=$ very accurate). Hachfeld et al. (23) reported both scales to have a good internal consistency with $\alpha=0.75$ for multicultural beliefs and $\alpha=0.88$ for stereotypes. Items of both scales can be seen in Table 3 .

\section{Teachers' Self-Efficacy and Enthusiasm}

We followed the conceptual propositions by Hachfeld et al. (19) to assess teachers' motivational orientations by measuring their perceived self-efficacy and enthusiasm for teaching refugee children. In our study, teachers' self-efficacy reflects their beliefs
TABLE 3 | Items assessing stereotypes and multicultural beliefs.

\section{Stereotypes}

1. In general, children from newly arrived families need more support.

2. In general, children from newly arrived families are an additional burden for the pre-school teacher.

3. Children from newly arrived families have more difficulties to cope with daily routines in pre-school.

\section{Multicultural beliefs}

1. During the apprenticeship, pre-school teachers should learn how to cope with cultural diversity.

2. During conversations with parents of different cultural backgrounds, I try to show consideration for their cultural background.

3. It is important for children to learn that people from other cultures can have different values.

4. In the pre-school classroom, it is important to be responsive to differences between cultures.

The table represents a translation of the original items.

in their capabilities to successfully organize and execute specific teaching tasks in a refugee context. For both constructs, we used the same items and item numbers as Hachfeld et al. (23), except for changing the wording from "students with a migration background" to "newly arrived children." Self-efficacy was assessed by four items (e.g., "I am capable of addressing the specific needs of newly arrived children").

In our study, enthusiasm for teaching refugee students reflects the degree of positive experiences during teaching. It was assessed by the two items "I enjoy caring for newly arrived children" and "I enjoy working with children from different backgrounds." Participants responded to the items of motivational orientations on a four-point Likert scale $(1=$ not accurate, $4=$ very accurate). Hachfeld et al. (19) reported both scales to have a good internal consistency with $\alpha=0.81$ for self-efficacy and $\alpha=0.90$ for enthusiasm.

\section{Children's Behavior Problems}

To assess perceptions of the refugee children's behavior problems, we used the German adaptation of the teacher-report Strengths and Difficulties Questionnaire [SDQ; $(42,43)$ ] for children aged 4 to 17 . The SDQ is a 25 -item behavioral screening tool, consisting of five subscales (emotional symptoms, conduct problems, hyperactivity/inattention, peer relationship problems, and prosocial behavior). Each subscale consists of five items on a 3-point Likert scale ranging from $0=$ "absolutely not true" to 2 = "absolutely true." Sum scores were computed for each SDQ subscale. Additionally, all scale scores except for prosocial behavior are summed up into a total difficulties score. In Western and Non-Western cultures, the SDQ has demonstrated good cross-cultural validity (44). For scoring and missing data detection, we used a script provided by the authors of the SDQ measure (sdqinfo.org). We thus erased subscales for individual children if more than three items per subscale were missing and only calculated the total difficulties score if no more than two items per subscale were missing. 


\section{Statistical Analysis}

All analyses were conducted in $\mathrm{R}$ version 1.2.1335. For the first hypothesis, we used multiple linear regression modeling to link teachers' stereotypes and multicultural beliefs to their selfefficacy and enthusiasm in separate models. For the second and third hypotheses, we used multiple linear regression modeling to, respectively, link teachers' SDQ ratings per subscale to their professional competence in separate models. Using the plot function for linear models, we visually inspected leverage plotted against standardized residuals and removed $n=3$ influential data points from the dataset. We then used the function gvlma of the package "Global Validation of Linear Model Assumptions" [gvlma; (45)] to examine assumptions for linear modeling. The procedure provides information on linearity, kurtosis and skewness of residuals, homoscedasticity, and scaling of the variables. Overall, the assumptions were acceptable across all models. We used the function vif of the car package for assessing multicollinearity. The variance inflation factor did not suggest multicollinearity and we used linear regression for modeling. As theory substantiated directions for our hypotheses, we used one-sided $p$-values $(\alpha=0.05)$ for interpreting all regression models. We used Bonferroni-Holm adjustments to control for $\alpha$-error inflation due to multiple testing (46). For regressing on the SDQ subscales, Bonferroni-Holm correction was used on all four subscales in one step as well as separately on total difficulties scores and prosocial behavior, as those were not part of the proposed hypotheses.

Additionally, we investigated the influence of teacher and child demographics. We conducted multiple linear regression analyses of teacher demographics (work experience, work experience with refugees, school-leaving qualification) on teachers' professional competence (enthusiasm, self-efficacy, stereotypes, multicultural beliefs) and the SDQ subscales. Additionally, we conducted multiple linear regression analyses of child demographics (age, gender, time spent in the pre-school facility, and country of origin) on SDQ subscales, as teachers reported on their professional competences before knowing which child they had to report on. Again, we used the function gvlma of the package gvlma and Bonferroni-Holm adjustments to control for $\alpha$-error inflation due to multiple testing.

Based on literature, correlations, and content-wise decisions, we chose three important teacher and four important child variables for additional regression analyses on confounders. We excluded other confounding variables because some were closely related by content and our study sample did not allow for the inclusion of a large number of predictors. The excluded variables were the age of the teachers (as it highly correlated with work experience; $r=0.932 p<0.001$ ), qualification of preschool teachers (as the majority of the teachers', 78.08\%, had the required pre-school exam and qualification is highly correlated with teachers' school-leaving qualification), teachers' role in the facilities (as it turned out that teachers who do administrative work were also involved in regular teaching; teachers' migration backgrounds (as the percentage of teachers with a migration background was 10.88\%); gender (as the proportion of men in our sample was too small for group comparisons, $4.76 \%$ ). Furthermore, we excluded the time children had spent in
Germany because this variable was only completed for $n=$ 104 children.

\section{RESULTS}

In Table 4, we report descriptive information on teachers' stereotypes, multicultural beliefs, self-efficacy, enthusiasm, and perceptions of children's behavior problems. Eight teachers had one missing value in one of the subscales on professional competence. Those teachers were excluded from the analysis of the respective subscale. See Table 4 for reliabilities of all scales. Regarding the measure for children's behavior problems, $n=26$ SDQ subscales for $n=20$ children were incomplete (equals $1.23 \%$ of all SDQ items).

In the first hypothesis, we expected stereotypes to be negatively associated with self-efficacy and enthusiasm, and multicultural beliefs to be positively associated with self-efficacy and enthusiasm. Our findings support this hypothesis (see Table 5).

Results on the second and third hypotheses are shown in Table 6. In the second hypothesis, we expected more stereotypes and less agreement with multicultural beliefs to be associated with the perception of more behavior problems. After BonferroniHolm correction, we found stereotypes to be positively associated with the perception of hyperactivity/inattention, but not with conduct, emotional or peer problems. Similarly, stereotypes were positively associated with the SDQ total difficulties score. Regression models linking multicultural beliefs to the SDQ subscales yielded no significant effects. Thus, the results only partially support the second hypothesis. In the third hypothesis, we expected higher self-efficacy and enthusiasm to be associated with the perception of fewer behavior problems. After Bonferroni-Holm correction, we only found self-efficacy to be negatively associated with the perception of hyperactivity/inattention, but no other subscale. Additionally, self-efficacy was positively associated with the SDQ total difficulties score. We found no significant links for enthusiasm.

Regression analyses of demographic data on teachers' professional competence and perception of behavior problems revealed that teachers' work experience with newly arrived children was positively associated with both teachers' stereotypes, $\beta=0.218, t_{(134)}=2.746, p=0.021$, and multicultural beliefs, $\beta$ $=0.209, t_{(134)}=2.749, p=0.020$. The other demographic teacher variables, work experience and school-leaving qualification, were neither associated with stereotypes nor multicultural beliefs. Furthermore, neither self-efficacy nor enthusiasm for teaching newly arrived children were significantly associated with any of the demographic teacher variables.

Teacher's work experience, $\beta=-0.012, t_{(134)}=-2.575$, $p=0.033$, was negatively associated with the perception of total difficulties. Children's male gender was positively associated with the perception of total difficulties, $\beta=5.045, t_{(114)}=$ 3.958, $p<0.001$. The perception of total difficulties was not associated with any other demographic child or teacher variable. For the SDQ subscales, children's male gender was positively associated with both perception of hyperactivity/inattention, $\beta=$ 
TABLE 4 | Teachers' professional competence for teaching refugee children and measures of children's behavior problems (SDQ).

\begin{tabular}{|c|c|c|c|c|c|c|c|}
\hline & & $\mathbf{M}$ & SD & Mdn & Min & Max & Std alpha \\
\hline \multirow[t]{2}{*}{ Beliefs and values } & Multicultural beliefs ${ }^{a}(n=146)$ & 5.23 & 0.69 & 5.25 & 1.5 & 6 & 0.66 \\
\hline & Stereotypes $^{\mathrm{b}}(n=146)$ & 2.92 & 0.66 & 3 & 1 & 4 & 0.67 \\
\hline \multirow[t]{2}{*}{ Motivational orientation } & Self-efficacy ${ }^{b}(n=143)$ & 3.26 & 0.52 & 3.25 & 1.5 & 4 & 0.76 \\
\hline & Enthusiasm $^{\mathrm{b}}(n=145)$ & 3.57 & 0.59 & 4 & 1 & 4 & $0.77^{\dagger}$ \\
\hline \multirow[t]{6}{*}{ externalizing } & Hyperactivity/inattention $^{c}(n=147)$ & 4.15 & 2.87 & 4 & 0 & 10 & 0.81 \\
\hline & Conduct problems ${ }^{c}(n=147)$ & 2.24 & 2.45 & 1 & 0 & 10 & 0.72 \\
\hline & Emotional symptoms ${ }^{c}(n=146)$ & 2.59 & 2.39 & 2 & 0 & 10 & 0.79 \\
\hline & Peer relationship problems ${ }^{c}(n=147)$ & 2.82 & 2.28 & 2 & 0 & 9 & 0.63 \\
\hline & Prosocial behavior $^{\mathrm{C}}(n=147)$ & 6.03 & 2.59 & 6 & 0 & 10 & 0.78 \\
\hline & Total difficulties score $(n=146)$ & 11.77 & 7.44 & 10.5 & 0 & 33 & 0.86 \\
\hline
\end{tabular}

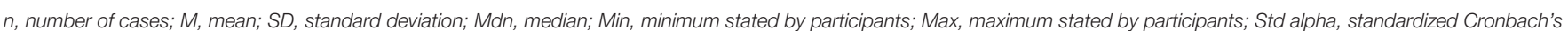

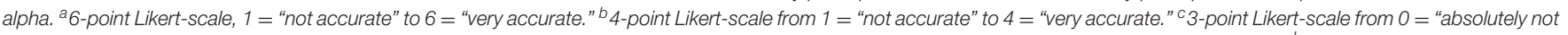

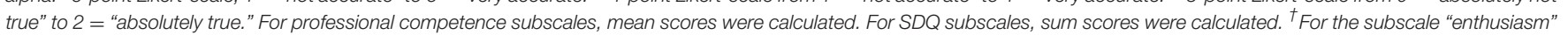
(two items) the correlation was calculated.

TABLE 5 | Multiple linear regression modeling for teachers' beliefs and values on teachers' motivational orientations.

\begin{tabular}{|c|c|c|c|c|c|c|}
\hline Outcome & Predictor & $b$ & $b(95 \%$ CI) & B & $p^{a}$ & Fit \\
\hline \multirow[t]{3}{*}{ Self-Efficacy } & (Intercept) & 2.5801 & {$[1.84,3.32]$} & -0.0057 & 0.944 & \\
\hline & Multicultural beliefs & 0.2190 & {$[0.09,0.35]$} & 0.2428 & $0.004^{\star \star}$ & \\
\hline & Stereotypes & -0.1563 & {$[-0.28,-0.03]$} & -0.1979 & $0.018^{\star \star}$ & Adj. $R^{2}=0.0787^{\star *}$ \\
\hline \multirow[t]{3}{*}{ Enthusiasm } & (Intercept) & 3.0725 & {$[2.32,3.83]$} & -0.0176 & 0.825 & \\
\hline & Multicultural beliefs & 0.2231 & {$[0.09,0.35]$} & 0.2411 & $0.003^{\star \star}$ & \\
\hline & Stereotypes & -0.2207 & {$[-0.34,-0.10]$} & -0.2726 & $<0.001^{\star \star}$ & Adj. $R^{2}=0.1173^{* * *}$ \\
\hline
\end{tabular}

b, unstandardized regression weights; $b$ (95\% Cl), 95\% confidence intervals for the unstandardized regression weights; $B$, standardized regression weights; $p$, two-sided p-values; Adj. $R^{2}$, adjusted $R^{2} .{ }^{* \star} p<0.01,{ }^{* \star *} p<0.001{ }^{a}$ Markings indicating significances following one-sided Bonferroni-Holm correction.

0.447, $t_{(114)}=4.461, p<0.001$, and the perception of conduct problems, $\beta=0.284, t_{(114)}=3.424, p=0.023$. The children's male gender was also negatively associated with the perception of prosocial behavior, $\beta=-0.352, t_{(114)}=-3.860, p=0.001$. Furthermore, children's age was significantly positively associated with the perception of prosocial behavior, $\beta=0.012, t_{(114)}=$ 3.217, $p=0.010$. Considering the country of origin, children from the African continent (Egypt, Eritrea, Morocco, Nigeria) were rated higher on the conduct problems scale and above the average when compared to all children, $\beta=0.363, t_{(114)}$ $=3.337, p=0.030$. All other associations between teacher or child demographics and teacher's professional competence and perception of behavior problems were insignificant.

\section{DISCUSSION}

The aims of our study were two-fold: In the first part, we investigated the links between pre-school teachers' negative stereotypes, multicultural beliefs, self-efficacy, and enthusiasm when teaching newly arrived refugee children. In the second part, we investigated the links between those variables and teachers' perceptions of newly arrived refugee children's behavior problems. We found teachers' stereotypes and multicultural beliefs to be associated with their self-efficacy and enthusiasm for teaching refugee children. Moreover, we found that both teachers' stereotypes and self-efficacy were associated with their perceptions of externalizing behavior problems.

\section{First Hypothesis}

Our first research aim was to investigate the links between teachers' stereotypes and multicultural beliefs toward refugee children as well as teachers' self-efficacy and enthusiasm for teaching refugee children. In line with previous research $(19,23-$ 25 ), we found that negative associations between stereotypes and motivational orientations as well as positive associations between multicultural beliefs and motivational orientations hold for pre-school teachers teaching newly arrived refugee children.

In several studies, teachers have reported feeling insecure when working with refugee children (14-16). Teachers' selfefficacy has accordingly been linked to their well-being (47), suggesting that not only the well-being of refugee children but also the entire pre-school facility could benefit from considering the links between teachers' beliefs, values, and motivational orientations. Working on teachers' stereotypes and cultural beliefs may likely improve their self-efficacy and enthusiasm, which in turn could foster teachers' well-being and allow them to be more confident when teaching refugee children. As classroom quality is linked to child performance $(48,49)$, pre-schools with teachers displaying less stereotypes and agreeing higher 
TABLE 6 | Multiple linear regression modeling for teachers' professional competence on teachers' SDQ ratings.

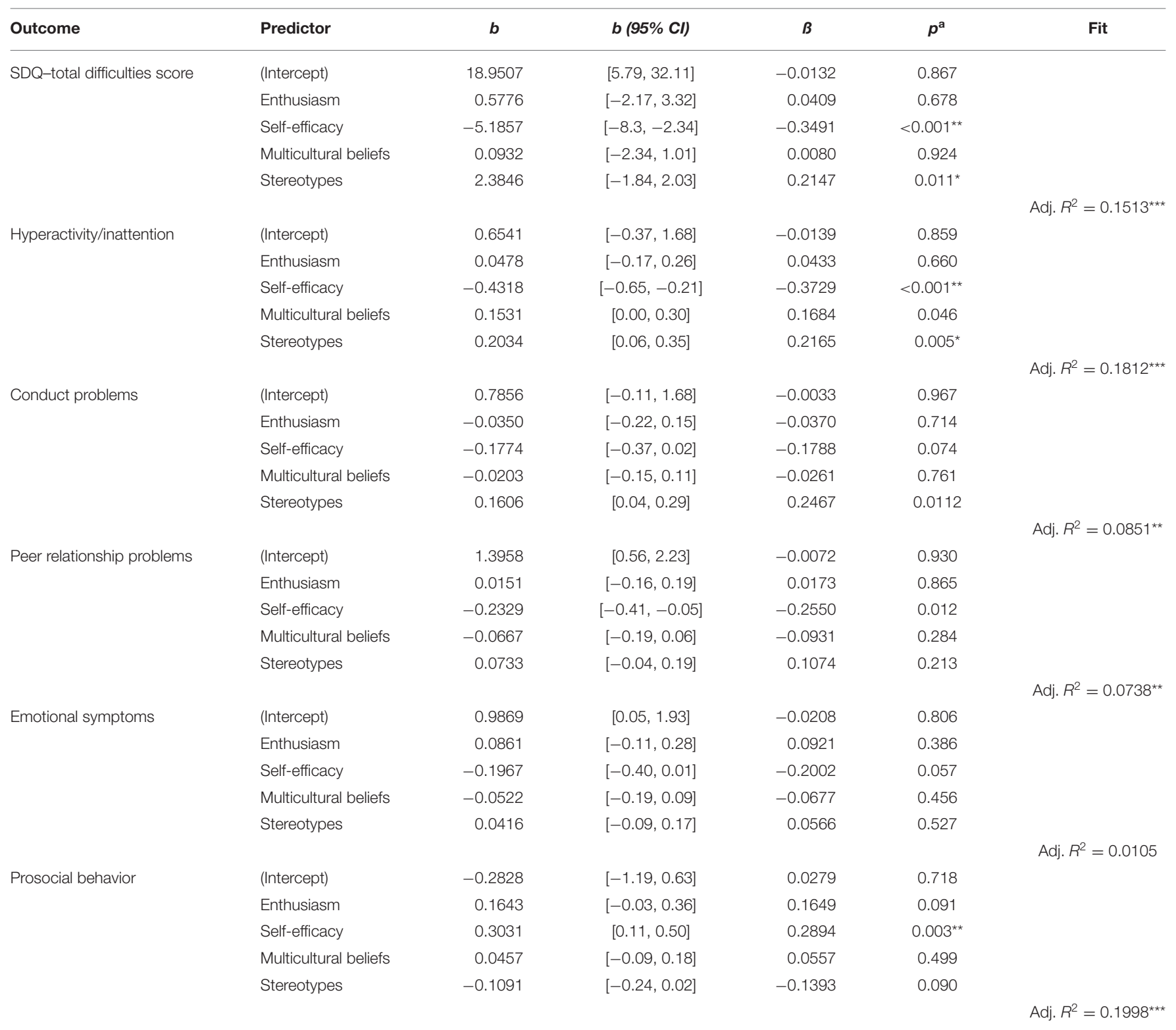

b, unstandardized regression weights; b (95\% Cl), 95\% confidence intervals for the unstandardized regression weights; $B$, standardized regression weights; $p$, two-sided $p$-values; Adj.

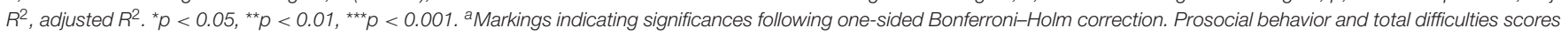
were not part of the hypothesis testing and Bonferroni-Holm adjustment was calculated separately.

with multicultural beliefs should be more effective in fostering academic and social-emotional learning in newly arrived refugee children. This is also likely to facilitate their transition into primary schools, as establishing a positive learning environment can be an important step toward catching up with learning delays and adapting to new and unfamiliar structures, e.g., during post-migration periods.

\section{Second Hypothesis}

We found that teachers with more stereotypes were also more likely to perceive hyperactivity/inattention and total difficulties in newly arrived refugee children. This is in line with findings that teachers reported more behavior problems for certain subgroups of migrant or minority children $(30,31)$ and more attention problems in refugee children (6). Negative expectations toward refugee children could lead to a selective focus on more problematic aspects of child behaviors. However, our data support this notion only for externalizing behavior. This partially inconsistent pattern could be explained by the higher visibility of children's externalizing behavior problems over their internalizing problems. Surprisingly, teachers with more stereotypes did not perceive more conduct problems, which are also externalizing problems. Nonetheless, our evidence on this is at the borderline as the link between stereotypes and 
conduct problems had reached significance before BonferroniHolm correction ( $p=0.012$, one-sided). Future research should re-examine whether stereotypes are related to the perceptions of conduct problems as well.

We found no significant effects on behavior problems for multicultural beliefs. To the best of our knowledge, no prior evidence exists regarding the links between multicultural beliefs and perceptions. Possibly, multicultural beliefs reflect teachers' ideas on how refugee children could be integrated best-without impacting how they perceive refugee children's behaviors, emotions, or performance. Indeed, the items measuring multicultural beliefs did not refer to student achievements. During and after transitioning into primary school, however, self-regulation and navigation through social situations can become challenging for refugee children (17). Additionally, perceiving refugee children as more divergent can influence their school outcomes and performance (37). Thus, detecting conduct and other behavior problems as unbiased as possible is crucial for promoting refugee children's learning and positive development. Previous research found that teachers exhibited stereotypes toward refugee children (37). Teacher training aiming at improving early education for refugee children should thus focus on reducing teachers' stereotypes, whereas our findings suggest that considering the degree of multicultural beliefs is less important.

\section{Third Hypothesis}

We found that teachers with higher self-efficacy were less likely to perceive hyperactivity/inattention and total difficulties in newly arrived refugee children. Consistently, previous research found that teachers' self-efficacy beliefs contributed to predicting their sense of efficacy in resolving cultural conflicts (32). Thus, teachers with higher self-efficacy might perceive certain child behaviors as less problematic, as they are more confident about their ability to solve potentially arising conflicts. In our investigation, perception bias could have also arisen when teachers with lower self-efficacy did not trust their abilities to detect behavior problems and thus reported lower scores in the SDQ subscales. Again, it is surprising that teachers with higher self-efficacy perceived less hyperactivity/inattention, but not less conduct problems. The items for identifying conduct problems refer to negative interactions with peers and adults. Items for hyperactivity/inattention do not differ between hyperactivity and inattention, while the latter might not be equally observable in German pre-school settings. In contrast to early education in other countries, pre-school curricula in Germany include more play-based learning. Hyperactivity/inattention symptoms might be less visible in play situations, as those are not extrinsically structured. This would allow for more interpretation and influence of stereotypes and self-efficacy on the teacher ratings.

We found no associations between teachers' enthusiasm and their perceptions of behavior problems. For the professional development of pre-school teachers, teachers' self-efficacy, rather than their enthusiasm, could be more important when preparing them for working with refugee children. However, teachers' enthusiasm was only assessed with two items and future research should consider expanding this measuring instrument.
Interestingly, we also found that higher self-efficacy of teachers was associated with their perceptions of children's prosocial skills. We found no previous literature on this link. Future research is needed to clarify whether this association can be replicated.

\section{Perception of Externalizing Behavior Problems}

We found hyperactivity/inattention to be associated with stereotypes and self-efficacy. This is in line with other evidence suggesting that teachers might be more sensitive to externalizing mental health problems than to internalizing mental health problems $(6,50)$. A possible reason could be that teachers' experiences are limited to pre-schools and that internalizing behavior might be more visible in home environments (51). In addition, children in our study were very young and at an age when externalizing behavior problems are more likely to be evident. Research suggests that young children tend to display externalizing behavior symptoms even when having internalizing disorders. For example, depressive symptoms were found to be manifest in externalizing and school problems in school-aged boys (52). As refugee children often show heightened mental health problems $(4,5)$, it is of special importance to raise teachers' awareness of possible underlying internalizing problems.

\section{Demographic Variables}

In addition to our main analyses, we found that children's age, gender, and region of origin, as well as their teachers' work experience and work experience with refugee children were partly associated with teachers' professional competence and SDQ ratings. Teachers' work experience with refugee children was moreover related to the higher agreement with multicultural beliefs and more negative stereotypes. Such patterns suggest that working with refugee children influences teachers' stereotypes and cultural beliefs in a way that teachers who are more experienced in working with refugee children could view children's different backgrounds more positively and consider them when interacting with these children, but also are more likely to assume that refugee children encounter more difficulties in pre-school and are thus in need of more support from their teachers. Moreover, we found that teachers' work experience was negatively linked to the perception of total difficulties. Increasing work experience could thus be linked to less stigmatization of newly arrived refugee children as "traumatized," a narrative that dominates public and partially also scientific discourses. Future research could clarify and further substantiate such associations.

Children's age was only positively associated with the perception of prosocial behavior, but not with SDQ problem scales. Possibly prosocial behavior is more visible in older children. Future research should re-investigate this possible link. Moreover, children's male gender was linked to increased perception of total difficulties and externalizing behavior problems (i.e., hyperactivity/inattention and conduct problems), as well as negatively associated with the perception of prosocial behavior. This is in line with previous research, in which teachers in day care centers perceived more externalizing behavior problems in boys (53). Also, teachers in elementary schools reported more hyperactivity/inattention for boys (54). We also 
found that newly arrived refugee children from Africa were reported to display more conduct problems. To the best of our knowledge, no previous literature has reported this link. Future research is needed to verify whether this finding can be replicated.

\section{Limitations and Future Directions}

This study measured teachers' perceptions with questionnaires, but these data were not corroborated by other methods. To address this limitation, teachers were asked to rate the behavior problems of the child that had been in the pre-school facility for the longest time. With this approach, we hoped to reduce the bias of choosing the child with the most visible mental health symptoms. Since we were unable to verify whether teachers followed this guideline, we cannot exclude a selection process. Additionally, it remains unclear whether pre-school teachers' professional competence influences their perceptions of behavior problems, or whether refugee children's behavior problems in pre-schools shape teachers' professional competence. This should be considered in future research. Classroom determinants such as composition could help to clarify those relations and should be addressed in future research. Nonetheless, by only sampling one teacher and child per pre-school group, we ensured better generalizability across pre-schools. Teachers' own migrant background could be related to their professional competence and the way they perceive refugee children's behavior problems. This could be investigated in future research. We also assessed work experience with refugee children as an eligibility criterion. In our sample, pre-school teachers stated to be very experienced with refugee children, and they displayed rather high agreements with multicultural beliefs as well as self-efficacy and enthusiasm for working with newly arrived children. Thus, the generalizability of our results could be limited to pre-school teachers having already worked to some extent with newly arrived children. As findings from other studies suggest that teachers often lack experience or education in teaching refugee children (14-16), future research could examine whether our findings can be generalized to teachers with less work experience with refugee children.

\section{CONCLUSION}

A large number of refugee children with heightened risks for behavior problems entered early education settings. Early education can decisively promote learning trajectories of preschool-aged refugee children. The role of teachers' motivations, beliefs, and perceptions toward those children and their assessment abilities of behavior problems demand additional

\section{REFERENCES}

1. Bundesamt für Migration und Flüchtlinge. Das Bundesamt in Zahlen 2019: Asyl. (2020). Available online at: https://www.bamf.de/SharedDocs/Anlagen/ DE/Statistik/BundesamtinZahlen/bundesamt-in-zahlen-2019-asyl.pdf?_ blob=publicationFile\&v $=4$ (accessed June 17, 2020). research. Teachers can provide important insights into the socioemotional needs of young refugee children during their postmigration periods. Our findings suggest that teachers' stereotypes and self-efficacy might be related to perceptions of refugee children's externalizing behavior problems. Possible perception biases might thus be addressed by fostering teachers' professional competence and considering teachers' stereotypes and selfefficacy in teacher training. Furthermore, researchers should consider teachers' professional competence when interpreting mental health assessments of refugee children conducted by teachers.

\section{DATA AVAILABILITY STATEMENT}

The raw data supporting the conclusions of this article will be made available by the authors, without undue reservation.

\section{ETHICS STATEMENT}

The studies involving human participants were reviewed and approved by the Ethics Committee of the Faculty of Psychology of the Ruhr-University Bochum. The participants provided their written informed consent to participate in this study.

\section{AUTHOR CONTRIBUTIONS}

SC contributed to manuscript writing and revision, study conceptualization, data analysis, and interpretation. BL contributed to study conceptualization, funding acquisition, manuscript feedback, and revision. AH contributed to study conceptualization and implementation. $\mathrm{CB}$ contributed to data curation and data analysis. JB contributed to study conceptualization, data analysis and interpretation, supervision of the research project, manuscript feedback, and revision. All authors contributed to the article and approved the submitted version.

\section{FUNDING}

We acknowledge support by the DFG Open Access Publication Funds of the Ruhr-University Bochum.

\section{ACKNOWLEDGMENTS}

We gratefully thank all pre-school teachers and childcare facilities for supporting our study. 
4. Wiegersma PA, Stellinga-Boelen AA, Reijneveld SA. Psychosocial problems in asylum seekers' children: the parent, child, and teacher perspective using the strengths and difficulties questionnaire. J Nerv Ment Dis. (2011) 199:85-90. doi: 10.1097/nmd.0b013e31820446d2

5. Kien C, Sommer I, Faustmann A, Gibson L, Schneider M, Krczal E, et al. Prevalence of mental disorders in young refugees and asylum seekers in European countries: a systematic review. Eur Child Adolesc Psychiatry. (2018) 28:1295-310. doi: 10.1007/s00787-018-1215-Z,

6. Buchmüller $\mathrm{T}$, Lembcke $\mathrm{H}$, Ialuna F, Busch J, Leyendecker B. Mental health needs of refugee children in specialized early education and care programs in Germany. J Immigr Minor Health. (2019) 22:22-33. doi: 10.1007/s10903-019-00896-4

7. Loeb S, Bridges M, Bassok D, Fuller B, Rumberger RW. How much is too much? The influence of pre-school centers on children's social and cognitive development. Econ Educ Rev. (2007) 26:52-66. doi: 10.1016/j.econedurev.2005.11.005

8. Magnuson KA, Ruhm C, Waldfogel J. Does prekindergarten improve school preparation and performance? Econ Educ Rev. (2007) 26:33-51. doi: 10.1016/j.econedurev.2005.09.008

9. Dearing E, McCartney K, Taylor BA. Does higher quality early child care promote low-income children's math and reading achievement in middle childhood? Child Dev. (2009) 80:1329-49. doi: 10.1111/j.1467-8624.2009.01336.x

10. KMK. Ständige Konferenz der Kultusminister der Länder in der Bundesrepublik Deutschland. Gemeinsamer Rahmen der Länder für die frühe Bildung in Kindertageseinrichtungen (2004). Available online at http://www.kmk. org/fileadmin/Dateien/veroeffentlichungen_beschluesse/2004/2004_06_03Fruehe-Bildung-Kindertageseinrichtungen.pdf (accessed June 17, 2020).

11. Schweinhart LJ. Benefits, Costs and Explanation of the High/Scope Perry Preschool Program. Tampa, FL: Meeting of the Society for Research in Child Development (2003)

12. Reynolds AJ, Temple JA, White BA, Ou S-R, Robertson DL. Age 26 costbenefit analysis of the child-parent center early education program. Child Dev. (2011) 82:379-404. doi: 10.1111/j.1467-8624.2010.01563.x

13. Birman BD, Tran, N. When worlds collide: academic adjustment of somali bantu students with limited formal education in a U.S. elementary school. Int J Intercult Rel. (2017) 60:132-44. doi: 10.1016/j.ijintrel.2017.06.008

14. Leavy A. 'When i meet them i talk to them': the challenges of diversity for preservice teacher education. Irish Educ Stud. (2005) 24:2-3. doi: 10.1080/03323310500435422

15. Levi TK. Preparing pre-service teachers to support children with refugee experiences. Alberta J Educ Res. (2019) 65:285-304.

16. Tobin J. Addressing the needs of children of immigrants and refugee families in contemporary ECEC settings: findings and implications from the children crossing borders study. Eur Early Child Educ. (2020) 28:10-20. doi: 10.1080/1350293X.2020.1707359

17. Busch J, Bihler LM, Lembcke H, Buchmüller T, Diers K, Leyendecker B. Challenges and solutions perceived by educators in an early childcare program for refugee children. Front Psychol. (2018) 9:1621. doi: 10.3389/fpsyg.2018.01621

18. Baak M, Miller E, Ziersch A, Due C, Masocha S, Ziaian T. The role of schools in identifying and referring refugee background young people who are experiencing mental health issues. J School Health. (2019) 90:172-81. doi: 10.1111 /josh.12862

19. Hachfeld A, Hahn A, Schroeder S, Anders Y, Kunter M. Should teachers be colorblind? How multicultural and egalitarian beliefs differentially relate to aspects of teachers' professional competence for teaching in diverse classrooms. Teach Teach Educ. (2015) 48:44-55. doi: 10.1016/j.tate.2015.02.001

20. Hachfeld A, Hahn A, Schroeder S, Anders Y, Stanat P, Kunter M. Assessing teachers' multicultural and egalitarian beliefs: the teacher cultural beliefs scale. Teach Teach Educ. (2011) 27:986-96. doi: 10.1016/j.tate.2011. 04.006

21. Tschannen-Moran M, Hoy AW, Hoy WK. Teacher efficacy: its meaning and measure. Rev Educ Res. (1998) 68:202-48. doi: 10.3102/003465430680 02202

22. Baumert J, Kunter M. "Das Kompetenzmodell von COACTIV," in Kunter M, Baumert J, Blum W, Klusmann U, Krauss S, Neubrand
M, editors. Professionelle Kompetenz von Lehrkräften. Ergebnisse des Forschungsprogramms COACTIV. Münster: Waxmann (2011). p. 29-53.

23. Hachfeld A, Schroeder S, Anders Y, Hahn A, Kunter M. Multikulturelle überzeugungen: herkunft oder überzeugung? welche rolle spielen der migrationshintergrund und multikulturelle überzeugungen für das unterrichten von kindern mit migrationshintergrund? Z Padagog Psychol. (2012) 26:101-20. doi: 10.1024/1010-0652/a000064

24. Bangura Y. Multicultural Education: The Relationship Between Preservice Teachers' Multicultural Self-Efficacy and Cultural Awareness When Teaching in Multicultural Classrooms. Bowling Green, OH: Bowling Green State University (2018).

25. Gutentag T, Horenczyk G, Tatar M. Teachers' approaches toward cultural diversity predict diversity-related burnout and self-efficacy. J Teach Educ. (2018) 69:4. doi: 10.1177/0022487117714244

26. Pajares MF. Teachers' beliefs and educational research: cleaning up a messy construct. Rev Educ Res. (1992) 62:307-32. doi: 10.3102/00346543062003307

27. Scott TM, Gage N, Hirn R, Han H. Teacher and student race as a predictor for negative feedback during instruction. School Psychol. (2019) 34:22-31. doi: $10.1037 /$ spq0000251

28. Anderson-Clark TN, Green RJ, Henley TB. The relationship between first names and teacher expectations for achievement motivation. J Lang Soc Psychol. (2008) 27:94-9. doi: 10.1177/0261927X07309514

29. Sprietsma M. Discrimination in grading: experimental evidence from primary school teachers. Empir Econ. (2013) 45:523-38. doi: 10.1007/s00181-012-0609-x

30. Chang DF, Sue S. The effects of race and problem type on teachers' assessments of student behavior. J Consult Clin Psychol. (2003) 71:235-42. doi: 10.1037/0022-006X.71.2.235

31. Stevens GWJM, Pels T, Bengi-Arslan L, Verhulst FC, Vollebergh WAM, Crijnen AAM. Parent, teacher and self-reported problem behavior in the Netherlands. Soc Psychiatry Psychiatr Epidemiol. (2003) 38:576-85. doi: 10.1007/s00127-003-0677-5

32. Siwatu KO, Starker TV. Predicting preservice teachers' self-efficacy to resolve a cultural conflict involving an African American student. Multicult Perspect. (2010) 12:10-7. doi: 10.1080/15210961003641302

33. Gibbs C. Explaining effective teaching: Self-efficacy and thought control of action. J Educ Enquiry. (2003) 4:2.

34. De Boer H, Bosker RJ, van der Werf MP. Sustainability of teacher expectation bias effects on long-term student performance. J Educ Psychol. (2010) 102:168-79. doi: 10.1037/a0017289

35. Sisask M, Värnik P, Värnik A, Apter A, Balazs J, Balint, et al. Teacher satisfaction with school and psychological well-being affects their readiness to help children with mental health problems. Health Educ. J. (2014) 73:382-93. doi: 10.1177/0017896913485742

36. Brown CL. Reducing the over-referral of culturally and linguistically diverse students (CLD) for language disabilities. NABE J Res Pract. (2004) 2:225-43.

37. Graham HR, Minhas RS, Paxton G. Learning problems in children of refugee background: a systematic review. Pediatrics. (2016) 137:e20153994. doi: 10.1542/peds.2015-3994

38. Bray-Clark N, Bates R. Self-efficacy beliefs and teacher effectiveness: Implications for professional development. Prof Educ. (2003) 26:13-22.

39. Mojavezi A, Tamiz MP. The impact of teacher self-efficacy on the students' motivation and achievement. Theor Pract Lang Stud. (2012) 2:483-91. doi: 10.4304/tpls.2.3.483-491

40. Keller MM, Goetz T, Becker ES, Morger V, Hensley L. Feeling and showing: A new conceptualization of dispositional teacher enthusiasm and its relation to students' interest. Learn Instruct. (2014) 33:29-38. doi: 10.1016/j.learninstruc.2014.03.001

41. Kunter M, Klusmann U, Baumert J, Richter D, Voss T, Hachfeld A. Professional competence of teachers: effects on instructional quality and student development. J Educ Psychol. (2013) 105:805-20. doi: $10.1037 / \mathrm{a} 0032583$

42. Goodman R. The strengths and difficulties questionnaire: a research note. J Child Psychol Psychiatry. (1997) 38:581-6. doi: 10.1111/j.1469-7610.1997.tb01545.x

43. Petermann U, Petermann F, Schreyer I. The German strengths and difficulties questionnaire (SDQ). Eur J Psychol Assess. (2010) 26:256-62. doi: $10.1027 / 1015-5759 / a 000034$ 
44. Woerner W, Fleitlich-Bilyk B, Martinussen R, Fletcher J, Cucchiaro G, Dalgalarrondo $\mathrm{P}$, et al. The strengths and difficulties questionnaire overseas: evaluations and applications of the SDQ beyond Europe. Eur Child Adolesc Psychiatry. (2004) 13:ii47-54. doi: 10.1007/s00787-004-2008-0

45. Peña EA, Slate EH. Global validation of linear model assumptions. J Am Stat Assoc. (2006) 101:341. doi: 10.1198/016214505000000637

46. Holm S. A simple sequential rejective multiple test procedure. Scand Stat Theory Appl. (1979) 6:65-70.

47. Zee M, Koomen HMY. Teacher self-efficacy and its effects on classroom processes, student academic adjustment, and teacher well-being: a synthesis of 40 years of research. Rev Educ Res. (2016) 86:981-1015. doi: 10.3102/0034654315626801

48. Mashburn AJ, Pianta RC, Hamre BK, Downer JT, Barbarin OA, Bryant $\mathrm{D}$, et al. Measures of classroom quality in prekindergarten and children's development of academic, language, and social skills. Child Dev. (2008) 79:732-49. doi: 10.1111/j.1467-8624.2008.01154.x

49. Rimm-Kaufman SE, Curby TW, Grimm KJ, Nathanson L, Brock LL. The contribution of children's self-regulation and classroom quality to children's adaptive behaviors in the kindergarten classroom. Dev Psychol. (2009) 45:95872. doi: 10.1037/a0015861

50. Loades ME, Mastroyannopoulou K. Teachers' recognition of children's mental health problems. Child Adolesc Ment Health. (2010) 15:150-6. doi: 10.1111/j.1475-3588.2009.00551.x

51. Becker A, Woerner W, Hasselhorn M, Banaschewski T, Rothenberger A. Validation of the parent and teacher SDQ in a clinical sample.
Eur Child Adolesc Psychiatry. (2004) 13:ii11-6. doi: 10.1007/s00787-0042003-5

52. Bailey MK, Zauszniewski JA, Heinzer MM, Hemstrom-Krainess AM. Patterns of depressive symptoms in children. J Child Adolesc Psychiatr Nurs. (2007) 20:86-95. doi: 10.1111/j.1744-6171.2007. 00090.x

53. Gross D, Fogg L, Garvey C, Julian W. Behavior problems in young children: an analysis of cross-informant agreements and disagreements. Res Nurs Health. (2004) 27:413-25. doi: 10.1002/nur.20040

54. DuPaul GJ, Jitendra AK, Tresco KE, Junod REV, Volpe RJ, Lutz JG. Children with attention deficit hyperactivity disorder: are there gender differences in school functioning? School Psych Rev. (2006) 35:2. doi: 10.1080/02796015.2006.12087993

Conflict of Interest: The authors declare that the research was conducted in the absence of any commercial or financial relationships that could be construed as a potential conflict of interest.

Copyright (c) 2021 Chwastek, Leyendecker, Heithausen, Ballero Reque and Busch. This is an open-access article distributed under the terms of the Creative Commons Attribution License (CC BY). The use, distribution or reproduction in other forums is permitted, provided the original author(s) and the copyright owner(s) are credited and that the original publication in this journal is cited, in accordance with accepted academic practice. No use, distribution or reproduction is permitted which does not comply with these terms. 